\title{
Baropodometria computadorizada
}

Donaldo Jorge Filho *

\section{Definição}

Teste que visa medir as pressdes desenvolvidas nos diferentes pontos da regiao plantar dos pés, quer em ortostatismo quer em marcha.

\section{Baropodometria estética}

Até bem pouco tempo era realizada em uma plataforma que registrava as pressões desenvolvidas nas plantas dos pés durante o ortostatismo, permitindo a detecção precoce de pontos de hiperpressão passiveis de desenvolver ú1ceras tróficas.

\section{Baropodometria dinâmica}

De aparecimento mais recente em nosso meio. Utiliza, ao invés de uma plataforma de força, palmilhas de material flexivel com sensores de pressção distribuidos por toda a superficie. Essas palmilhas são originalmente confeccionadas para pés tamanho 52 $=35 \mathrm{~cm}$, mas podem ser recortadas com uma tesoura comum segundo linhas pré demarcadas permitindo serem utilizadas até em crianças com pés tamanho $11=7,5 \mathrm{~cm}$. Sobre a superficie de uma palmilha em seu tamanho original há cerca de 960 células sensiveis A pressão dos pés contra o solo.

Durante os testes as palmilhas devem ser colocadas dentro dos calçados, entre as plantas dos pés a serem analisados e o solo.

A concentraçio das células baroceptoras difere para cada região da palmilha. Esta distribuição segue informaçdes, dadas por estudos realizados anteriormente em outros dispositivos de avaliaviio, acerca da distribuivfio normal das pressbes pelas superficies plantares dos pis. A espessura dessas cilulas baroceptoras é da ordem de quatro milésimos de polegada, sendo praticamente ignoradas pelos corpúsculos sensitivos da região plantar dos pés.

Integrando todas estas células existe a malha de condutores que é distribuida em vias paralelas numa expansio lateral situada no limite do 1/3 médio com posterior das palmilhas. Essa expansao leva os sinais gerados pelos pés sobre as palmilhas até unidades fixadas aos tornozelos com perneiras de tecido e velcro. Essas unidades destinam-se à captação, processamento e transmissão dos sinais que fa-

Divisão de Medicina de Reabilitação - HC.FMUSP

Médico Fisiatra. Mestre em Medicina de Reabilitação

Endereço para correspondência:

Rua Diderot, 43

CEP 04116-030 - São Paulo / SP 
zem a interface mecânica entre os sensores e o resto do sistema. Um cabo coaxial f'ino e flexivel, com seis metros de comprimento, leva esses sinais até o computador onde são analisados e processados pelo Programa F-scan de Baropodometria. Esse fio dá uma liberdade de aproximadamente oito metros de marcha ininterrupta ao paciente, o que permite o registro de considerável número de passos completos para anilise pelo F-scan. 0 Programa F-scan opera em ambiente Windows, preferencialmente em um microcomputador 486 com 8 megabites de memória RAM para que se tenha um processamento ágil. Permite o registro de cerca de 100 diferentes arranjos por segundo.

A baropodometria computadorizada pelo Fscan permite obter dados qualitativos e quantitativos dos eventos que ocorrem no ciclo da marcha, sendo útil na avaliação funcional de pés dolorosos, pés neuropáticos e de pés com anomalias posturais, na detecção dos distúrbios da transferência do peso para o solo. Também se presta à análise da marcha de pacientes amputados deambulando com próteses e método tipo de distúrbios que afetem as função dos pés a marcha. Por meio da baropodometria computadorizada torna-se possivel a detecção precoce de pontos de hiperpressão anormal, permitindo que se tomem providências de caráter profilático. Mostra-se útil também nas avaliações pós-cirúrgicas corretivas das anomalias dos pés. 0 sistema F-scan, reunindo um dispositivo mecânico de aquisição de dados periféricos (Palmilhas Receptoras das Pressões Plantares) a um microcomputador possibilita que se faça, de forma mais objetiva e bastante simplificada, as análises qualitativa e quantitativa de diversos parâmetros da marcha, tais como : força vertical ; deslocamento e oscilações do centro de força ; pressões desenvolvidas em diferentes pontos das regiões plantares ; cadência da marcha (número de passos por minuto) ; assimetria de descarga do peso corporal nas regiões plantares dos pés ; duração do ciclo completo da marcha , das fases de apoio e de balanço e, inclusive, de cada periodo isolado dessas fases da marcha. Avalia também a pressão dos pés nos vários eventos da marcha bem como o tempo decorrido em cada uma delas, como o contato inicial (Toque de Calcâneo), o contato total (Médio Apoio), o desprendimento do calcanhar e do hálux. Ademais, permite a elaboração de gráficos de Tempo x Pressão e de Força Vertical x Pressão.

A baropodometria computadorizada pelo Fscan leva vantagem sobre as análises de marcha feitas com interruptores ("footswiches") colocados sob os antepés e sob os retropés porque, como as células de pressão são distribuidas por toda a superficie das palmilhas, no F-scan os eventos são registrados na totalidade das regiões plantares, visualizados dinamicamente no monitor do microcomputador. As imagens geradas aparecem em janelas que utilizam diferentes côres para representar as variações de pressões exercidas nos pés, escalas numéricas quantificando os eventos sob análise e, abaixo das janelas, a correspondentes representação gráfica. Ademais, sendo o sistema computadorizado, as anormalidades encontradas no exame podem ser impressas a cores por uma impressora de jato de tinta e enviadas aos médicos assistentes do paciente junto com o laudo. Esta apresentação facilita em muito as indicações de palmilhas, solados especiais, gessos de contato total e até de órteses que, modificando as condições de descarga anormais, previnem a ocorrência de úlceras de pressão ou mesmo contribuem para a cicatrização daquelas porventura existentes.

Fugindo ao tema da Baropodometria, mas á guisa de informação, achamos oportuno mencionar que o Sistema F-scan de Baropodometria Computadorizada recebeu, recentemente, um melhoramento que permite medições das pressões exercidas pelas regiões isquiáticas e periisquiáticas dos pacientes com lesões medulares durante o repouso sentado em cadeira de rodas. Esse melhoramento é de especial importância na execução de assentos especiais para adaptação nas cadeiras de rodas os quais compensam as anomalias de descarga decorrentes de distúirbios posturais de paraplégicos e tetraplégicos, permitindo a prevenção on a cicatrização das úlceras de pressão nessas regiões do corpo, tal como se faz nas úlceras plantares com a prescrição de palmilhas, solados especiais anti-impacto, etc.

\section{Bibliografia recomendada}

I. MALERBI, D. : D ANDREA GREVE, J.M. : MATIELO, A. ; ELIAS, C. ; LEIVAS, T.P.; Saraiva, S. ; Wajchenberg. B.L. - Avaliação da pressão plantar durante a marcha em pacientes diabéticos com e sem neuropatia - IX Congresso Brasileiro de Diabetes, São Paulo, 1993.

2. D'ANDREA GREVE, J6IIA M. ; LEIVAS, T.P. - Baropodometria Computadorizada - Parâmetros Normais. Movimentação, 5: 3-4, 1994

3. D'ANDREA GREVE, JÚIIA M. : LEIVAS, T.P: IMAMURA, M. : CARVALHO JR., A.E.; FERNANDES, T.D.; SALOMĀO. 0.- POdometry: a critical evaluation of it's use in Hansen's disease. São Paulo Medical Journal / APM, 112: 500-3, 1994

4. JORGE FILHO, D. - Próteses Ortopédicas de baixo custo (Estudo Critico do Pé de Jaipur nos Amputados Transtibiais) - Tese de Mestrado apresentada á UNIFESP/Escola Paulista de Medicina. Curso de Pós Graduação em Ciências da Saúde, Area de Reabilitaçāo, Cap. III., págs. 18-70, 1996.

5. CONTI,S.F.; MARTIN, R.L.; CHAYTON,E.R.; HUGHES, C.; LUTTRELL.L. - Plantar pressure measurements during ambulation in weightbearing conventional short leg casts and total contact casts. Foot \& Ankle International, $17: 464-9,1996$

6. MUELLER, M.J.\& STRUBE, M.J.- Generalizability of in-shoe peak pressure measures using the F-scan system. Clinical Biomechanics, 3 : 159-164, 1996

7. RAGAVAN, R. : BENOIT, P.: OHANNA, F. - Clinical applications of real-time measurements of seating pressures among spinal cord injury patients. Centre PROPARA (Spinal Unit). Montpellier, France, September, 1995. 